\title{
Prevalence and predictors of coronary artery disease in patients with a calcium score of zero
}

\author{
Maria Salomé Leal de Carvalho • Pedro de Araújo Gonçalves • Hector M. Garcia-Garcia • \\ Pedro Jerónimo de Sousa • Helder Dores • António Ferreira • Nuno Cardim • \\ Miguel Mota Carmo • Ana Aleixo • Miguel Mendes · Francisco Pereira Machado • \\ José Roquette $\cdot$ Hugo Marques
}

Received: 15 March 2013/Accepted: 19 July 2013/Published online: 26 July 2013

(C) Springer Science+Business Media Dordrecht 2013

\begin{abstract}
The absence of coronary calcification is associated with an excellent prognosis. However, a calcium score of zero does not exclude the presence of coronary artery disease (CAD) or the possibility of future cardiovascular events. Our aim was to study the prevalence and predictors of coronary artery disease in patients with a calcium score of zero. Prospective registry consisted of 3,012 consecutive patients that underwent cardiac CT (dual source CT). Stable patients referred for evaluation of possible CAD that had a calcium score of zero $(n=864)$ were selected for this analysis. The variables that were statistically significant were included in a multivariable logistic regression model. From 864 patients with a calcium score of zero, $107(12.4 \%)$ had coronary plaques on the contrast CT $(10.8 \%, \mathrm{n}=93$ with nonobstructive $\mathrm{CAD}$ and $1.6 \%, \mathrm{n}=14$ with obstructive $\mathrm{CAD}$ ). By logistic regression analysis, the independent predictors of $\mathrm{CAD}$ in this population were age $>55$ years [odds ratio (OR) $1.63(1.05-2.52)$ ], hypertension [OR 1.64 (1.05-2.56)] and dyslipidemia [OR 1.54 (1.00-2.36)]. In the presence of these 3 variables, the probability of having coronary plaques was $21 \%$. The absence of coronary artery
\end{abstract}

M. S. L. de Carvalho ( $₫)$ · P. de Araújo Gonçalves ·

P. J. de Sousa - H. Dores - A. Aleixo - M. Mendes

Centro Hospitalar Lisboa Ocidental, Lisboa, Portugal

e-mail: mariasalomecarvalho@gmail.com

P. de Araújo Gonçalves · A. Ferreira · N. Cardim ·

F. P. Machado $\cdot$ J. Roquette $\cdot$ H. Marques

Hospital da Luz, Lisboa, Portugal

P. de Araújo Gonçalves · M. M. Carmo · A. Aleixo

CEDOC - Chronic Diseases Research Center - FCM-Nova,

Lisboa, Portugal

H. M. Garcia-Garcia

Thoraxcenter, Erasmus MC, Rotterdam, The Netherlands calcification does not exclude the presence of coronary artery disease, but the prevalence of obstructive disease is very low. In this population, the independent predictors of CAD in the setting of a calcium score of zero were hypertension, dyslipidemia, and age above 55 years. In the presence of these 3 predictors, the probability of having CAD was almost 2 times higher than in the general population.

Keywords Zero calcium score · Coronary artery disease $\cdot$ Noncalcified plaque

\section{Introduction}

Coronary artery disease (CAD) is a major cause of death in developed countries and it is expected to remain the most important disease in the upcoming years [1].

Quantification of coronary artery calcium [calcium scoring $(\mathrm{CaSc})]$ can provide a measure of the atherosclerotic plaque burden, since coronary arterial calcification occurs almost exclusively in atherosclerotic plaques [2,3]. Also, it has been demonstrated in many large clinical trials, that $\mathrm{CaSc}$ is a strong predictor of cardiovascular events [4-7].

On the other hand, the absence of calcium in the coronary arteries, although it does not rule out atherosclerotic disease, is consistent with an excellent long-term prognosis [8] and has a high sensitivity and negative predictive value for excluding obstructive CAD. This fact prompted some recent guidelines to suggest that a calcium score of zero might exclude the need for coronary angiography in symptomatic patients [9]. Nevertheless, in previous studies, a high variation was reported in the incidence of obstructive CAD in patients with a CaSc of zero, ranging from 2 to $32 \%$ [10-15]. For instance, in the recent CONFIRM registry, it was shown that in patients with a $\mathrm{CaSc}$ of zero, obstructive CAD is 
possible and is associated with increased cardiovascular events [16]. The aim of this study was to assess the prevalence and predictors of coronary artery disease in a population of stable patients referred for evaluation of possible CAD who had a calcium score of zero.

\section{Methods}

Study design and patient population

Single center prospective registry including 3,012 consecutive patients undergoing dual source coronary CT angiography (CCTA) from February 2007 to March 2012. For this analysis, 864 stable patients (with symptoms and/or positive or inconclusive stress tests) referred for evaluation of possible CAD that had a calcium score of zero were included.

Exclusion criteria included: (1) preoperative CAD assessment prior to noncoronary valvular or aortic surgery $(\mathrm{n}=51)$; (2) evaluation of possible CAD in cardiomyopathies (dilated cardiomyopathy or hypertrophic cardiomyopathy) $(\mathrm{n}=162)$; (3) cardiac $\mathrm{CT}$ for atrial fibrillation ablation $(\mathrm{n}=330)$; (4) previous myocardial infarction and/or revascularization procedures $(\mathrm{n}=257)$; (5) suspected ACS $(\mathrm{n}=70)$; (6) other indications $(\mathrm{n}=102)$. Patients with atrial fibrillation or other significant arrhythmias during scan acquisition or artifacts that significantly compromised image quality were also excluded, as every patient with a $\mathrm{CaSc}>0$ (Fig. 1).

The study was approved by the local ethics committee and all patients gave a written informed consent.

A detailed medical history with a questionnaire investigating risk factors was obtained from the patients to assess for the presence of: (1) Diabetes mellitus (defined as a fasting glucose level of $\geq 126 \mathrm{mg} / \mathrm{dl}$ or the need for insulin or oral hypoglycemic agents) [17]; (2) Dyslipidemia (defined as a total cholesterol level $\geq 200 \mathrm{mg} / \mathrm{dl}$ or treatment with lipidlowering drugs) [18]; (3) Hypertension (defined as blood pressure $\geq 140 / 90 \mathrm{mmHg}$ or the use of antihypertensive medication) [19]; (4) Obesity (body mass index $\geq 30 \mathrm{~kg} / \mathrm{m}^{2}$ ); (5) positive family history of premature $\mathrm{CAD}$ (defined as the presence of CAD in first-degree relatives younger than 55 (male) or 65 (female) years of age) [20]; (6) smoking (defined as previous (less $<1$ year) or current smoker).

Pre-test probability of CAD was determined using both the modified Diamond and Forrester [21] and the Morise score [22]. The cardiovascular risk was assessed with the Heart Score [23]. In the modified Diamond-Forrester, patients were classified into very low $(<5 \%)$, low $(<10 \%)$, intermediate (10-90\%) and high probability $(>90 \%)$. For the Morise score, patients were classified into low (scores 0-8), intermediate (scores 9-15) and high probability (scores $\geq 16$ ). For the Heart Score, the cut-off of $\geq 5 \%$ (high-risk) was used.
Fig. 1 Patient selection and study design

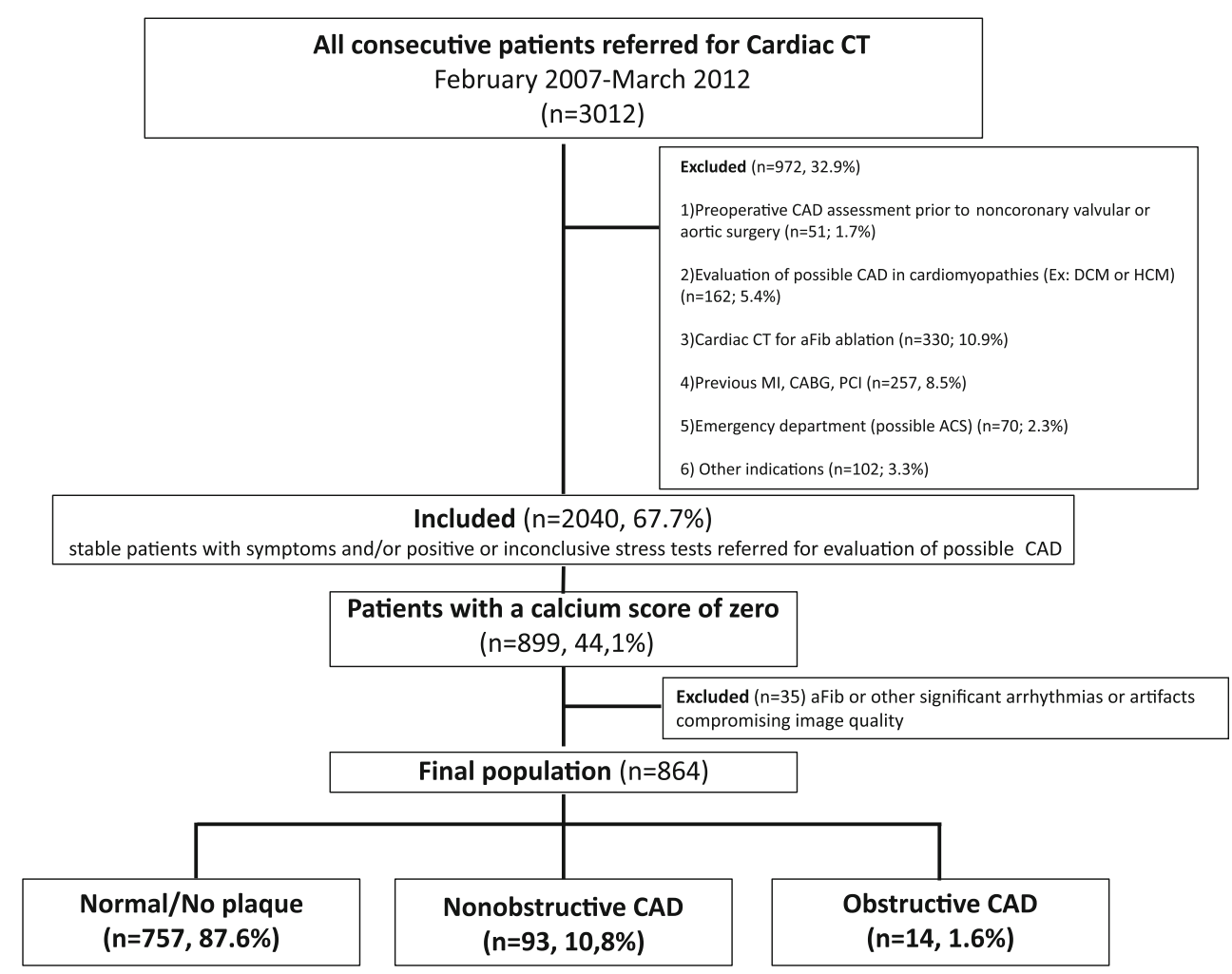


Scan protocol and image reconstruction

All scans were performed with the first generation of dualsource scanner (Somatom Definition, Siemens Medical, Germany), with the patient in dorsal decubitus and in deep inspiration breath-hold.

The calcium score acquisition consisted of step and shoot-prospective ECG triggering at $70 \%$ of the R-R interval if the heart rate was below 80 beats per min (bpm) or at $40 \%$ of the R-R interval if the heart rate was higher. From the topogram, a cranio-caudal scan was obtained from the carina to the plane just below the heart silhouette, with $120 \mathrm{kV}$ and $128 \mathrm{mAs} /$ rot tube current, with CAREDose 4D mAs modulation. The value of the calcium score was obtained with the analysis of consecutive non-contrast $3 \mathrm{~mm}$ slices, with a reconstruction b35f Kernel and a small (cardiac) FOV, with a dedicated software (CaSc-Siemens), where every area at least with $3 \mathrm{~mm}^{2}$ within a coronary vessel with a density above $130 \mathrm{HU}$ (Hounsfield Units) was selected.

For CCTA, sublingual nitroglycerin was administered to all patients, except when contraindicated, and intravenous metoprolol ( $5 \mathrm{mg}$, with a titration dose up to $20 \mathrm{mg}$ ) was administered in patients with heart rate $>70 \mathrm{bpm}$.

During the scan acquisition, a bolus of iodinated contrast was injected at a $6 \mathrm{ml} / \mathrm{s}$ infusion rate, followed by a $50-\mathrm{ml}$ saline flush. The dose of contrast was calculated according to the following formula: (acquisition time $+6 \mathrm{~s}$ delay) $\times$ flow $(6 \mathrm{ml} / \mathrm{s})$. A ROI was defined in the ascending aorta for the bolus trigger technique, set at $120 \mathrm{HU}$.

Dose reduction strategies-including electrocardiogram-gated tube current modulation, reduced tube voltage, and prospective axial triggering-were used whenever feasible.

Mean estimated radiation dose was $0.8 \pm 0.5 \mathrm{mSv}$ for $\mathrm{CaSc}$ and $4.6 \pm 3.8 \mathrm{mSv}$ for CT scan. Mean contrast dose was $96.2 \pm 13.6 \mathrm{ml}$ and heart rate was $67.8 \pm 12.9 \mathrm{bpm}$.

Transaxial images were reconstructed with a temporal resolution of $83 \mathrm{~ms}$ and slice thickness of $0.75 \mathrm{~mm}$ with $0.4 \mathrm{~mm}$ increments. Post-processing was carried out using Circulation ${ }^{\circledR}$ software, with multiplanar reconstructions, maximum intensity projection and volume rendering technique. All scans were analysed independently in the same session by both a cardiologist and a radiologist with level III equivalent experience by the Society of Cardiovascular Computed Tomography. In case of disagreement, a joint reading was performed and a consensus decision was reached.

In each coronary artery segment, coronary atherosclerosis was defined as tissue structures $>1 \mathrm{~mm}^{2}$ that existed either within the coronary artery lumen or adjacent to the coronary artery lumen that could be discriminated from surrounding pericardial tissue, epicardial fat, or the vessel lumen itself [24]. Coronary atherosclerotic lesions were quantified for stenosis by visual estimation. Percent obstruction of coronary artery lumen was based on a comparison of the luminal diameter of the segment exhibiting obstruction to the luminal diameter of the most normal-appearing site immediately proximal to the plaque. Obstructive CAD was defined by presence of at least one plaque with $\geq 50 \%$ stenosis.

\section{Statistical analysis}

Continuous variables with normal distribution were expressed as mean \pm standard deviation. Categorical variables were expressed as percentages and their frequencies were compared with the Chi square test.

Binary logistic regression models were built to elucidate independent predictors of CAD without coronary calcification.

The objective of this model was the assessment of clinical variables that aid to predict the presence of CAD in patients with a calcium score of zero. All the demographic, risk factors and clinical variables present in Table 2 that had a $p<0.1$ in univariate analysis were included in a multivariate logistic regression model (Enter method).

Statistical analysis was performed with SPSS 17.0 software for Windows (SPSS Inc., Chicago, IL, USA).

\section{Results}

Baseline and procedural characteristics

In the final study population of 864 patients, most of the patients were female (55\%) and mean age was $53.8 \pm 11.0$ years. The prevalence of traditional risk factors was low, with only $9.0 \%$ of patients with diabetes. This was predominantly a low risk population with few high risk patients (only $9.0 \%$ with the Morise score and $3.1 \%$ with the modified Diamond-Forrester had a high CAD probability). Likewise, most of the patients were not considered as high cardiovascular risk, as assessed by the Heart Score (only $11.9 \%$ had a Heart Score $\geq 5 \%$ )-Table 1 .

Coronary plaques were detected on CCTA in 107 patients $(12.4 \%): 10.8 \%(\mathrm{n}=93)$ with nonobstructive CAD and $1.6 \%(n=14)$ with obstructive CAD—Fig. 2. Considering the degree of stenosis of the obstructive CAD group, $64 \%(\mathrm{n}=9)$ had a $50-70 \%$ stenosis and $36 \%$ $(\mathrm{n}=5)$ a $>70 \%$ stenosis. Considering the extent of disease, all these patients had obstructive CAD in only 1 vessel and $93 \%$ had a single lesion. Regarding the distribution, most of the obstructive CAD lesions were found in proximal or mid segment locations $(87 \%)$, and the most affected artery was the right coronary artery $50 \%(\mathrm{n}=7)$. 
Table 1 Demographic, clinical and CCTA characteristics of the study population

\begin{tabular}{ll}
\hline & All patients $(\mathrm{n}=864)$ \\
\hline Demographic & \\
Age & $53.8 \pm 11.0$ \\
Male sex & $389(45.0)$ \\
Risk factors & \\
Obesity (BMI $\geq 30)$ & $160(18.5)$ \\
Diabetes & $78(9.0)$ \\
Hypertension & $459(53.1)$ \\
Dyslipidemia & $454(52.5)$ \\
Smoking & $206(23.8)$ \\
Family history of premature CAD & $284(32.9)$ \\
Chest pain & \\
Asymptomatic & $441(51.0)$ \\
Noncardiac & $194(22.5)$ \\
Atypical & $182(21.1)$ \\
Typical & $47(5.4)$ \\
CAD probability-Morise & \\
Score $\geq 16$ & $78(9.0)$ \\
Score 9-15 & $446(51.6)$ \\
Score 0-8 & $340(39.4)$ \\
CAD probability-modified Diamond Forrester \\
Very low \\
Low
\end{tabular}

Values are mean $\pm \mathrm{SD}$ or $\mathrm{n}(\%)$

$B M I$ body mass index, $C A D$ coronary artery disease, $C V$ cardiovascular, CCTA coronary computed tomography angiography, bpm beats per minute, $m S v$ milisievert

Left anterior descendent was affected in 5 patients, while left main was affected in one patient and the circumflex artery in other patient.

There were no significant differences in the prevalence of CAD in patients referred for CCTA because of positive/ inconclusive stress tests $(93 / 722=12.9 \%)$ versus patients referred without previous stress tests $(14 / 142=9.9 \%)$, $p=0.403$.
Prevalence of CAD

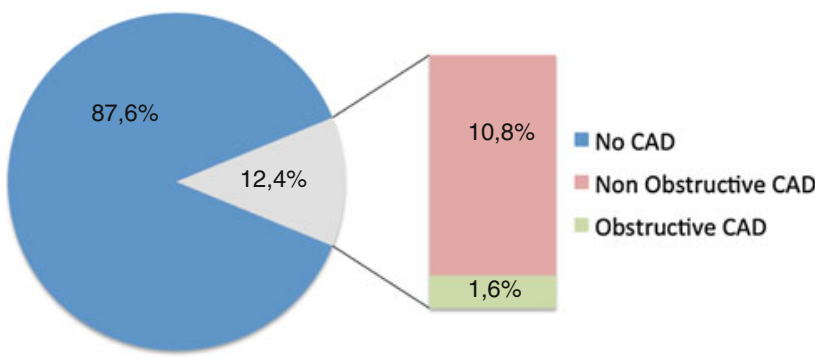

Fig. 2 Distribution of CT angiographic findings

Table 2 Prevalence of CAD according to the pretest probability (Morise)

\begin{tabular}{lll}
\hline Pretest probability & Nonobstructive CAD & Obstructive CAD \\
\hline Low $(\mathrm{n}=340)$ & $27(7.9 \%)$ & $6(1.8 \%)$ \\
Intermediate $(\mathrm{n}=446)$ & $64(14.3 \%)$ & $6(1.3 \%)$ \\
High $(\mathrm{n}=78)$ & $16(20.5 \%)$ & $2(2.6 \%)$ \\
$p$ & 0.002 & 0.708 \\
\hline
\end{tabular}

We further analyzed the distribution of CAD in the different pretest probability subgroups. Using those defined by Morise, the prevalence of CAD (any plaque) was 7.9, 14.3 and $20.5 \%$ in low, intermediate and high pretest probability patients, respectively. Regarding obstructive $\mathrm{CAD}$, a higher prevalence was also found in patients with high pretest probability, but this increase was not statistically significant (Table 2).

Univariate analysis

Patients with CAD were older (prevalence of age $\geq 55$ years 64 vs. $47 \%, p=0.001$ ) than patients without $\mathrm{CAD}$ and had a higher prevalence of dyslipidemia (65 vs. $51 \%$, $p=0.010$ ) and hypertension (67 vs. $51 \%, p=0.002$ ).

The pre-test CAD probability assessed both by the Morise score and the modified Diamond-Forrester was higher in the CAD group and these patients had a 2-4 times higher probability of being of a high CAD probability group. Cardiovascular risk, estimated by the Heart Score, was also significantly higher in patients with CAD. Although there was a trend in this group towards a higher prevalence of diabetes and male gender, these differences were not statistically significant-Table 3 .

Multivariate analysis

By multivariate analysis, the independent predictors of CAD in patients with a calcium score of zero were age $\geq 55$ (OR $1.631,95 \%$ CI 1.054-2.524, $p=0.028)$, hypertension (OR 
Table 3 Univariate analysis

\begin{tabular}{|c|c|c|c|}
\hline & $\begin{array}{l}\text { No CAD } \\
(\mathrm{n}=757)\end{array}$ & $\begin{array}{l}\text { CAD } \\
(\mathrm{n}=107)\end{array}$ & $p$ \\
\hline \multicolumn{4}{|l|}{ Demographic } \\
\hline Age $\geq 55$ years & $355(47.0)$ & $68(63.6)$ & 0.0 \\
\hline Male gender & $335(44.3)$ & $54(50.5)$ & 0.2 \\
\hline \multicolumn{4}{|l|}{ Risk factors } \\
\hline Diabetes & $64(8.5)$ & $14(13.1)$ & 0.1 \\
\hline Obesity (BMI $\geq 30$ ) & $139(18.4)$ & $21(19.6)$ & 0.7 \\
\hline Hypertension & $387(51.1)$ & $72(67.3)$ & $\mathbf{0 . 0 0}$ \\
\hline Dyslipidemia & $385(50.9)$ & $69(64.5)$ & 0.01 \\
\hline Smoking & $184(24.3)$ & $22(20.6)$ & 0.46 \\
\hline $\begin{array}{l}\text { Family history of } \\
\text { premature CAD }\end{array}$ & $248(32.8)$ & $36(33.6)$ & 0.91 \\
\hline \multicolumn{4}{|l|}{ Symptoms } \\
\hline Chest pain & $371(49.0)$ & $52(48.6)$ & 1.00 \\
\hline \multicolumn{4}{|c|}{ CAD probability-Morise } \\
\hline Score $\geq 16$ & $62(8.2)$ & $16(15.0)$ & 0.00 \\
\hline Score $9-15$ & $382(50.5)$ & $64(59.8)$ & \\
\hline Score $0-8$ & $313(41.3)$ & $27(25.2)$ & \\
\hline \multicolumn{4}{|c|}{ CAD probability—modified Diamond Forrester } \\
\hline Very low & $171(22.6 \%)$ & $17(15.9)$ & 0.00 \\
\hline Low & $342(45.2)$ & $49(45.8)$ & \\
\hline Intermediate & $225(29.8)$ & $32(29.9)$ & \\
\hline High & $18(2.4)$ & $9(8.4)$ & \\
\hline \multicolumn{4}{|l|}{$\mathrm{CV}$ risk } \\
\hline Heart Score $\geq 5$ & 79 (10.4) & $24(22.4)$ & 0.00 \\
\hline
\end{tabular}

Values are mean $\pm \mathrm{SD}$ or $\mathrm{n}(\%)$

$C A D$ coronary artery disease, $B M I$ body mass index, $C V$ cardiovascular

Bold indicates $p$ value with statistical significance

$1.641,95 \%$ CI 1.051-2.560, $p=0.029)$ and dyslipidemia (OR 1.538, $95 \%$ CI 1.002-2.361, $p=0.049$ ) (Fig. 3). In the presence of these 3 variables $(\mathrm{n}=176$ patients, $20.4 \%$ of the population), the probability of having coronary plaques was $21 \%$ (vs. $12.4 \%$ in the total studied population). We also analyzed the prevalence of CAD according to the presence of none, one, two or three of these risk factors. The results are shown in Table 4.

\section{Discussion}

In this single center cohort of stable patients without known CAD, referred for cardiac CT angiography, we found a very low prevalence of obstructive CAD $(1.6 \%)$ in the subset with a CaSc of zero. When considering the degree of stenosis, only $0.6 \%$ had a stenosis $>70 \%$.

The prevalence and clinical significance of obstructive $\mathrm{CAD}$ on coronary $\mathrm{CT}$ angiography among patients with a

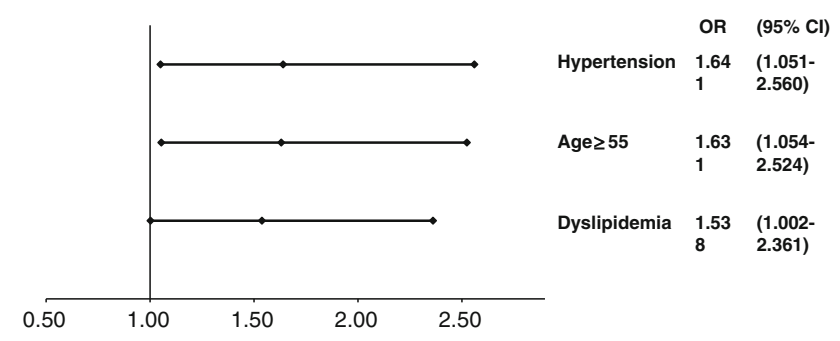

Fig. 3 Independent predictors of CAD in patients with a $\mathrm{CaSc}$ of zero

calcium score of zero has been evaluated in several cohorts, but with conflicting results, depending on the population included. Data from Nieman et al. [14], the CONFIRM registry [16], Rubinshtein et al. [13] and Akram et al. [11], are in line with our results, with a low prevalence of obstructive CAD $(2,3.5,7.2$ and $8.2 \%$, respectively). Our prevalence was even lower, and this might be explained by a high prevalence of patients with a low pretest probability of CAD.

In contrast, in the work of Harberl et al. [10] and Gottlieb et al. [12], there was a high prevalence of CAD (32 and $19.4 \%$, respectively), which can be related to the fact that these studies included patients referred for conventional angiography, including patients with possible acute coronary syndromes.

In our population, the prevalence of $\mathrm{CAD}$ in patients with positive/inconclusive stress tests (exercise electrocardiography in most cases) was not significantly different from that of patients referred to CCTA without previous tests, as in the study from Nieman et al. [14].

Calcium scoring enables a noninvasive quantification of the total coronary atherosclerotic burden, although it underestimates the burden of disease, by not measuring noncalcified plaques [25]. Nevertheless, it has been shown to outperform traditional risk stratification tools, such as clinical risk factor assessment, ankle-brachial index, carotid intima-media thickness and high-sensitivity C-reactive protein, as a predictor of cardiovascular events $[4,5]$.

Our data suggests that, although the absence of calcium does not exclude the presence of CAD, it was associated with a very low probability of obstructive lesions. This was especially true in cases of low and intermediate pretest CAD probability, as in the study from Werkhoven et al. [15] in which the prevalence of obstructive CAD, in the absence of calcium, was only 3.4 and $3.8 \%$ in patients with low and intermediate pretest CAD probability, respectively. This is in line with the excellent prognosis that has been demonstrated for patients with a calcium score of zero [8].

In our population, older age ( $\geq 55$ years), hypertension and dyslipidemia were independent predictors of CAD in 
Table 4 Prevalence of CAD according to the presence of risk factors found to be independent predictors

\begin{tabular}{lllll}
\hline Independent preditors & No CAD & Nonobstructive CAD & Obstructive CAD & Total \\
\hline 0 & $158(96.9 \%)$ & $5(3.1 \%)$ & $0(0 \%)$ & 163 \\
1 & $210(86.8 \%)$ & $25(10.3 \%)$ & $7(2.9 \%)$ & 242 \\
2 & $250(88.3 \%)$ & $28(9.9 \%)$ & $5(1.8 \%)$ & 283 \\
3 & $139(79.0 \%)$ & $35(19.9 \%)$ & $2(1.1 \%)$ & 176 \\
& 757 & 93 & 14 & 864 \\
\hline
\end{tabular}

Fig. 4 Non-calcified plaque on cardiac CT (on the right) in a patient with a CaSc of zero; the angiography (on the left) confirmed the presence of a $50-70 \%$ stenosis in the midRCA; intravascular ultrasound with virtual histology (in the middle) suggests the presence of microcalcifications

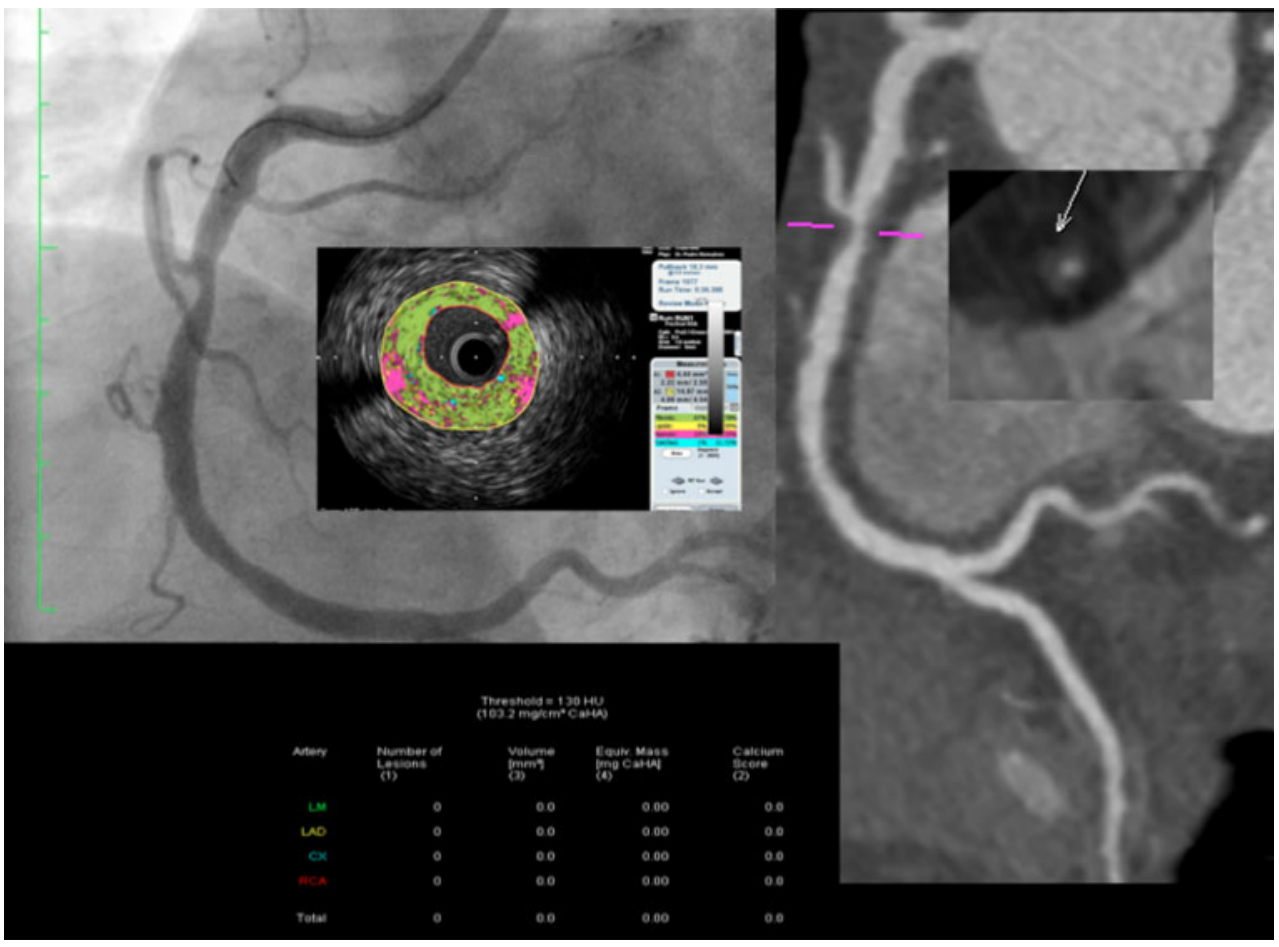

this subset of patients without calcium, and in the presence of these 3 predictors, the probability of having CAD was almost 2 times higher than in the general population. Nevertheless, the odds ratios for the independent predictors were rather modest and other traditional CAD risk factors were not found to be independent predictors. This way, we could hypothesize that coronary plaques without calcium could be a different phenotypical subset of CAD. Another possibility could be that these patients with coronary plaques in the absence of calcium represent $\mathrm{CAD}$ at earlier stages, since calcium is considered to be associated with more advanced forms of atherosclerotic lesions [2]. In fact, in our population, all the patients with obstructive CAD had only 1 vessel disease, most (93\%) with a single lesion, and only a minority ( $36 \%$ ) had $>70 \%$ stenosis.

One last hypothesis could be that these plaques can have microcalcifications below the threshold of cardiac CT spacial resolution, as in the case example (Fig. 4), in which small spots of calcium were only detected by intravascular ultrasound (IVUS) virtual histology.

\section{Limitations}

There are a number of limitations related to this report: (1) this is a single center retrospective study with medium size cohort; (2) our population in mainly of low CAD probability and $\mathrm{CV}$ risk; the very low percentage of obstructive CAD found can not be extrapolated to cohorts with more patients with higher CAD probability and CV risk (3) the definition of CAD was made using CCTA and not invasive angiography, which may lead to false-positive findings, although this is unlikely in the absence of calcium; (4) lack of prognostic information, since we did not evaluate the prognostic importance of obstructive CAD in patients with a $\mathrm{CaSc}$ of zero. 


\section{Conclusions}

In this population of stable patients referred for evaluation of possible CAD that had a calcium score of zero, $12.4 \%$ had coronary plaques and $1.6 \%$ had obstructive $(\geq 50 \%)$ CAD.

Therefore, and despite the known high negative predictive value of $\mathrm{CaSc}$ for coronary events, the absence of coronary artery calcification does not exclude the presence of coronary artery disease, but the prevalence of obstructive disease is very low.

In this population, we found that age $\geq 55$, hypertension, dyslipidemia were independent predictors of CAD in the setting of a calcium score of zero. In the presence of these 3 predictors, the probability of having CAD was almost 2 times higher than in the total studied population.

Conflict of interest All the authors declare that they have no conflict of interest.

\section{References}

1. Lloyd-Jones D, Adams R, Carnethon M, De Simone G, Ferguson TB, Flegal K et al (2009) Heart disease and stroke statistics2009 update: a report from the American heart association statistics committee and stroke statistics subcommittee. Circulation 119(3):480-486

2. Stary HC, Chandler AB, Dinsmore RE, Fuster V, Glagov S, Insull W Jr et al (1995) A definition of advanced types of atherosclerotic lesions, a histological classification of atherosclerosis. A report from the committee on vascular lesions of the council on arteriosclerosis, American heart association. Arterioscler Thromb Vasc Biol 15:1512-1531

3. Budoff M, Jollis JG, Dowe D, Min J for the VCT study group (2013) Diagnostic accuracy of coronary artery calcium for obstructive disease: results from the ACCURACY trial. Int $\mathbf{J}$ Cardiol 166(2):505-508

4. Detrano R, Guerci AD, Carr JJ, Bild DE, Burke G, Folsom AR et al (2008) Coronary calcium as a predictor of coronary events in four racial or ethnic groups. N Engl J Med 358:1336-1345

5. Yeboah J, McClelland RL, Polonsky TS, Burke GL, Sibley CT, O'Leary D et al (2012) Comparison of novel risk markers for improvement in cardiovascular risk assessment in intermediaterisk individuals. JAMA 308:788-795

6. Shaw LJ, Raggi P, Schisterman E, Berman DS, Callister TQ (2003) Prognostic value of cardiac risk factors and coronary artery calcium screening for all-cause mortality. Radiology 228(3):826-833

7. Petretta M, Daniele S, Acampa W, Imbriaco M, Pellegrino T, Messalli G et al (2012) Prognostic value of coronary artery calcium score and coronary CT angiography in patients with intermediate risk of coronary artery disease. Int J Cardiovasc Imaging 28(6):1547-1556

8. Sarwar A, Shaw LJ, Shapiro MD, Blankstein R, Hoffmann U, Cury RC et al (2009) Diagnostic and prognostic value of absence of coronary artery calcification. J Am Coll Cardiol Imaging 2:675-688

9. National Institute for Health and Clinical Excellence (2010) Chest pain of recent onset. Assessment and diagnosis of recent onset chest pain or discomfort of suspected cardiac origin.
London: NICE. Available from: http://www.nice.org.uk/guid ance/CG95

10. Haberl R, Tittus J, Böhme E, Czernik A, Richartz BM, Buck J et al (2005) Multislice spiral computed tomographic angiography of coronary arteries in patients with suspected coronary artery disease: an effective filter before catheter angiography? Am Heart J 149:1112-1119

11. Akram K, O'Donnell RE, King S, Superko HR, Agatston A, Voros S (2009) Influence of symptomatic status on the prevalence of obstructive coronary artery disease in patients with zero calcium score. Atherosclerosis 203:533-537

12. Gottlieb I, Miller JM, Arbab-Zadeh A, Dewey M, Clouse ME, Sara L et al (2009) The absence of coronary calcification does not exclude obstructive coronary artery disease or the need for revascularization in patients referred for conventional coronary angiography. J Am Coll Cardiol 44:627-634

13. Rubinshtein R, Gaspar T, Halon DA, Goldstein J, Peled N, Lewis BS (2007) Prevalence and extent of obstructive coronary artery disease in patients with zero or low calcium score undergoing 64-slice cardiac multidetector computed tomography for evaluation of a chest pain syndrome. Am J Cardiol 99:472-475

14. Nieman K, Galema TW, Neefjes LA, Weustink AC, Musters P, Moelker AD et al (2009) Comparison of the value of coronary calcium detection to computed tomographic angiography and exercise testing in patients with chest pain. Am J Cardiol 104(11): 1499-1504

15. van Werkhoven J, de Boer S, Schuijf J, Cademartiri F, Maffei E, Jukema $\mathbf{J}$ et al (2010) Impact of clinical presentation and pretest likelihood on the relation between calcium score and computed tomographic coronary angiography. Am J Cardiol 106(12): $1675-1679$

16. Villines TC, Hulten EA, Shaw LJ, Goyal M, Dunning A, Achenbach S et al (2011) Prevalence and severity of coronary artery disease and adverse events among symptomatic patients with coronary artery calcification scores of zero undergoing coronary computed tomography angiography: results from the CONFIRM (coronary CT angiography evaluation for clinical outcomes: an international multicenter) registry. J Am Coll Cardiol 58:2533-2540

17. Gavin J, Alberti K, Davidson M, DeFronzo R, Drash A, Gabbe S et al (1997) Report of the expert committee on the diagnosis and classification of diabetes mellitus. Diabet Care 20(7):1183-1197

18. Grundy S, Becker D, Clark L, Cooper R, Denke M, Howard W et al (2001) Expert panel on detection Evaluation and treatment of high blood cholesterol in Adults. Executive summary of the third report of the National Cholesterol Education Program (NCEP) expert panel on detection, evaluation, and treatment of high blood cholesterol in adults (adult treatment panel III) JAMA 285(19):2486-2497

19. European Society of Hypertension-European Society of Cardiology Guidelines C (2003) European Society of HypertensionEuropean Society of Cardiology guidelines for the management of arterial hypertension (2003). J Hypertens 21(6):1011-1053

20. Taylor AJ, Bindeman J, Feuerstein I, Cao F, Brazaitis M, O'Malley PG (2005) Coronary calcium independently predicts incident premature coronary heart disease over measured cardiovascular risk factors: mean 3-year outcomes in 18 the prospective army coronary calcium (PACC) project. J Am Coll Cardiol 46(5):807-814

21. Gibbons RJ, Balady GJ, Bricker JT, Chaitman BR, Fletcher GF, Froelicher VFet al (2002) American college of cardiology/American heart association task force on practice guidelines (committee to update the 1997 exercise testing guidelines). ACC/AHA, guideline update for exercise testing: summary article: a report of the American college of cardiology/American heart association task force on practice guidelines. Circulation 106(14):1883-1892 
22. Morise AP, Haddad WJ, Beckner D (1997) Development and validation of a clinical score to estimate the probability of coronary artery disease in men and women presenting with suspected coronary disease. Am J Med 102(4):350-356

23. Perk J, De Backer G, Gohlke H, Graham I, Reiner Z, Verschuren $M$ et al (2012) European Guidelines on cardiovascular disease prevention in clinical practice (version 2012): the fifth joint Task Force of the European society of cardiology and other societies on cardiovascular disease prevention in clinical practice (constituted by representatives of nine societies and by invited experts) Developed with the special contribution of the European association for cardiovascular prevention and rehabilitation (EACPR). Eur Heart J 33(13):1635-1701

24. Min JK, Shaw LJ, Devereux RB, Okin PM, Weinsaft JW, Russo DJ et al (2007) Prognostic value of multidetector coronary computed tomographic angiography for prediction of all-cause mortality. J Am Coll Cardiol 50(12):1161-1170

25. Rumberger JA, Simons DB, Fitzpatrick LA, Sheedy PF, Schwartz RS (1995) Coronary artery calcium area by electron-beam computed tomography and coronary atherosclerotic plaque area. Circulation 92:2157-2162 